\title{
Ultraviolet to Long-Wave Infrared Photodetectors Based on Three-Dimensional Dirac Semimetal/Organics Thin Film Heterojunction
}

Ming Yang ${ }^{1}$, Jun Wang ${ }^{1,2 *}$, Yunkun Yang ${ }^{3}$, Qi Zhang ${ }^{4}$, Chunhui $\mathrm{Ji}^{1}$, Guorong $\mathrm{Wu}^{4}$, Yuanjie $\mathrm{Su}^{1}$, Jun Gou ${ }^{1}$, Zhiming $\mathrm{Wu}^{1,2}$, Kaijun Yuan ${ }^{4}$, Faxian $\mathrm{Xiu}^{3,5 *}$ and Yadong Jiang 1,2

${ }^{I}$ School of Optoelectronic Science and Engineering, University of Electronic Science and Technology of China .Chengdu 610054, P.R. China

${ }^{2}$ State Key Laboratory of Electronic Thin Films and Integrated Devices, University of Electronic Science and Technology of China. Chengdu 610054, P.R. China.

${ }^{3}$ State Key Laboratory of Surface Physics and Department of Physics, Fudan University . Shanghai 200433, P.R. China.

${ }^{4}$ State key Laboratory of Molecular Reaction Dynamics, Dalian Institute of Chemical Physics, Chinese Academy of Sciences. Dalian 116023, P.R. China.

${ }^{5}$ Collaborative Innovation Center of Advanced Microstructures.Nanjing 210093, China. 


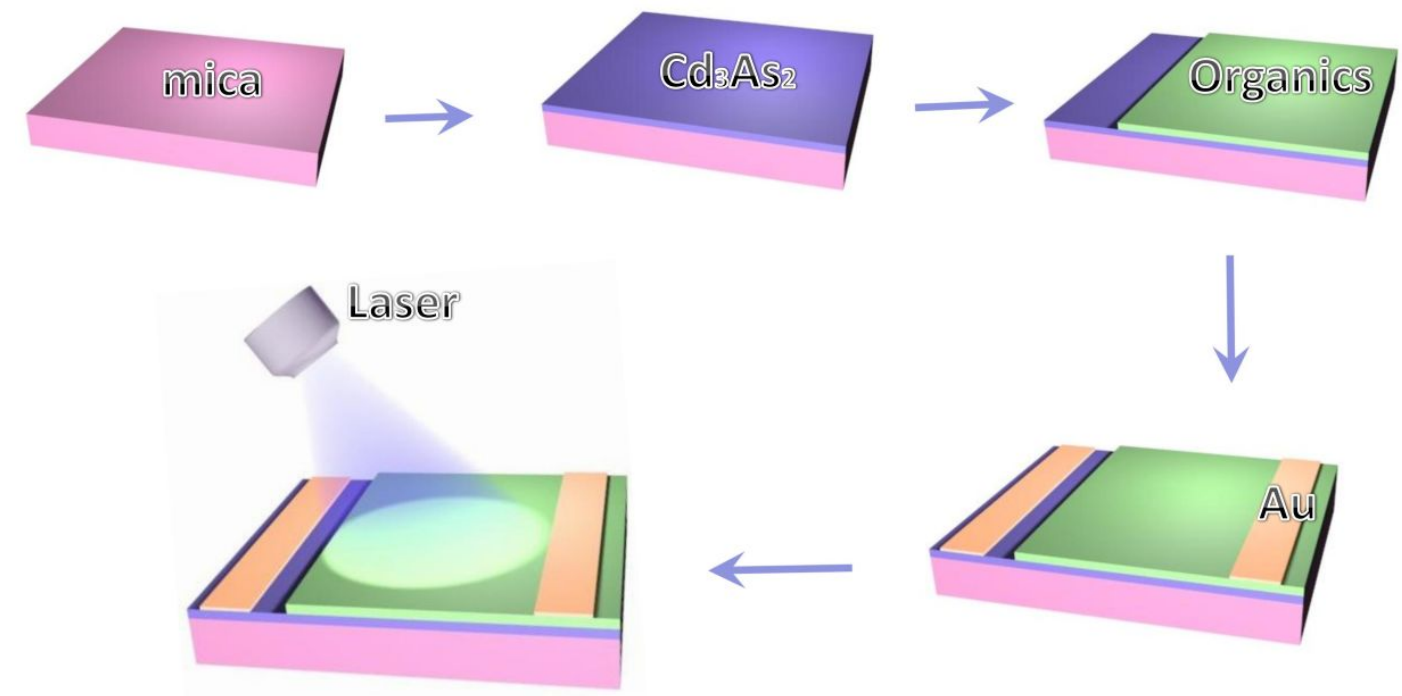

Figure S1. Schematic diagram of the preparation process of $\mathrm{Cd}_{3} \mathrm{As}_{2}$ /organics heterojunction thin film photodetectors. The mica substrate with $100 \mathrm{~nm} \mathrm{Cd}{ }_{3} \mathrm{As}_{2}$ thin film is placed into the thermal evaporation or spraying equipment with metal mask to evaporate a $100 \mathrm{~nm}$ thick layer of organics thin film. Then, electron beam evaporation is used to evaporate Au electrodes plated on the upper sides of the respective materials. Finally, the $\mathrm{Cd}_{3} \mathrm{As}_{2}$ thin film as well as $\mathrm{Cd}_{3} \mathrm{As}_{2} /$ organics heterojunction photodetector possesses a channel with $500 \mu \mathrm{m}$ long and $100 \mu \mathrm{m}$ wide.

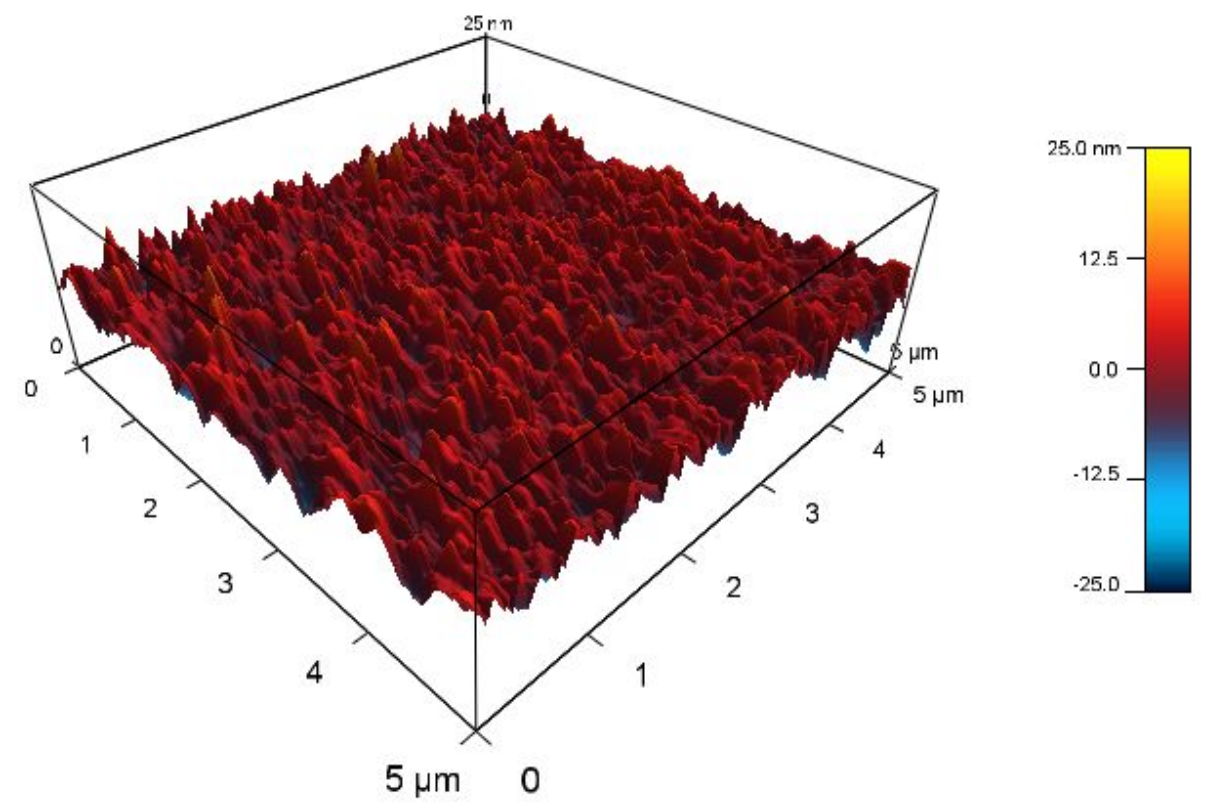

Figure S2. The AFM surface topography of $\mathrm{Cd}_{3} \mathrm{As}_{2}$ thin films' surface.The RMS of $\mathrm{Cd}_{3} \mathrm{As}_{2}$ thin film is $3.1 \mathrm{~nm}$. 
(a)

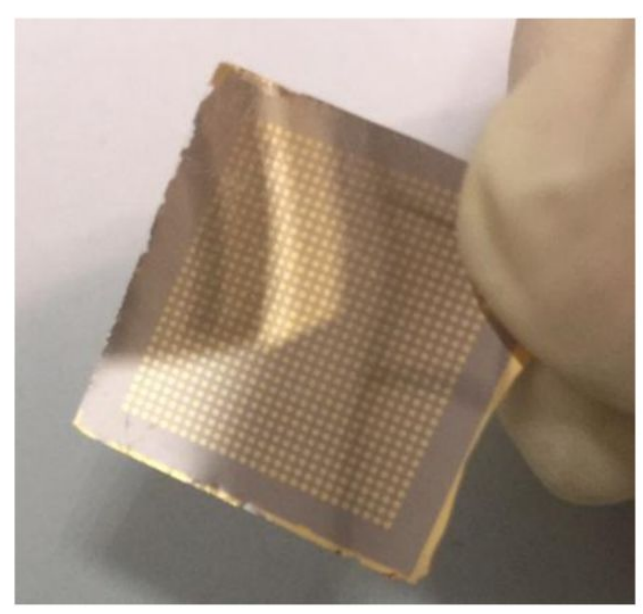

(b)

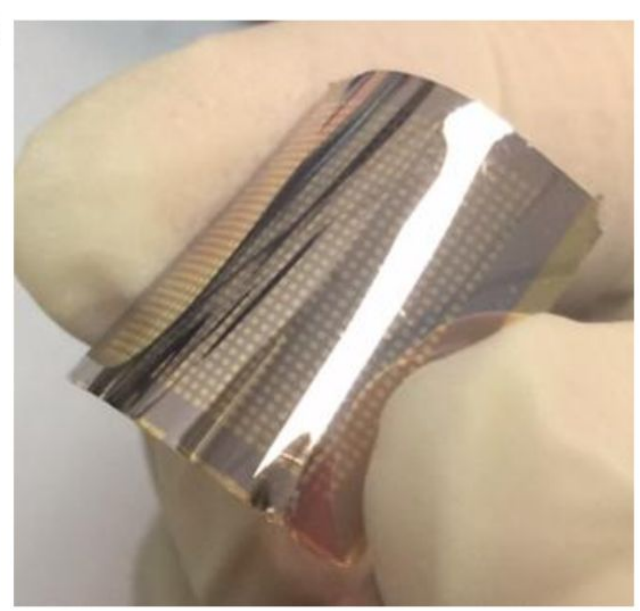

Figure S3. Display of $\mathrm{Cd}_{3} \mathrm{As}_{2}$ thin film devices. The array $\mathrm{Cd}_{3} \mathrm{As}_{2}$ thin film devices have good flexibility.

(a)

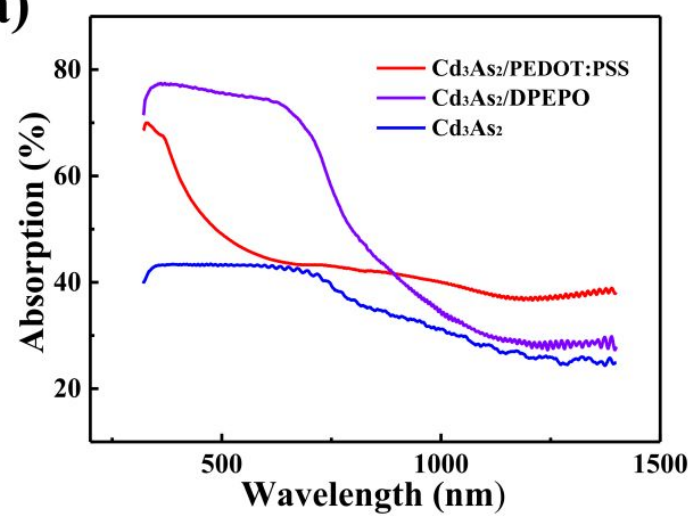

(b)

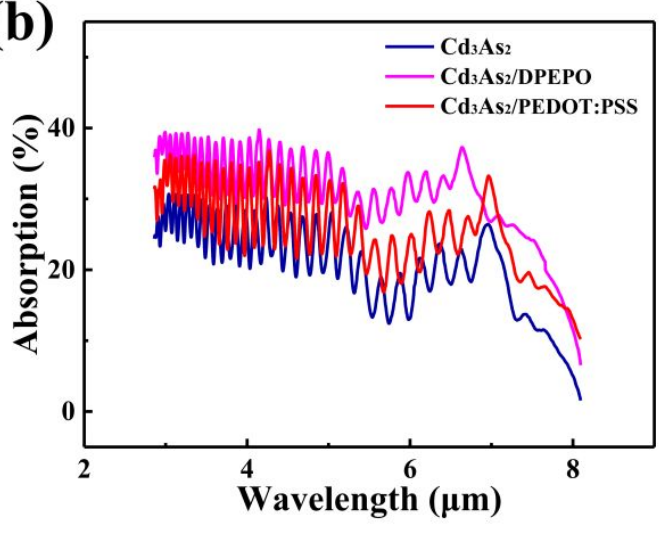

Figure S4. The absorption carves of $\mathrm{Cd}_{3} \mathrm{As}_{2} / \mathrm{DPEPO}, \mathrm{Cd}_{3} \mathrm{As}_{2} / \mathrm{PEDOT}$ :PSS recombination thin films and $\mathrm{Cd}_{3} \mathrm{As}_{2}$ thin film at different waveband. (a) VL to near IR waveband absorption, from $300 \mathrm{~nm}$ to $1400 \mathrm{~nm}$.(b) IR waveband absorption, from $2.8 \mu \mathrm{m}$ to $8 \mu \mathrm{m}$.

Absorption test method: First test the air and mica substrate reflectivity and transmissivity and then test the samples of absorptivity and reflectivity, respectively. Then the formula for computing the absorption rate of $\mathrm{A}=1-\mathrm{R}-\mathrm{T}$ (including $\mathrm{A}$ representative of the material absorption rate, $\mathrm{R}$ is for material reflectivity, $\mathrm{T}$ on behalf of the materials transmissivity), calculate the material absorption. The fluctuation of the real data is mainly due to the influence of mica substrate, which is easy to be resolved in layers. When the light source is irradiated, it is easy to form fluctuations on the surface of and between layers of mica. Although the base effect has been deducted in the experiment, it is not guaranteed to completely eliminate the fluctuation effect. Furthermore, the various classes thin films' absorption (300 nm to 
$1400 \mathrm{~nm}$ ) measured by the ultraviolet-visible light spectrophotometer (Shimadzu UV2600). Moreover, the infrared absorption is measured by the Fourier transform infrared spectrometer (IS50R FTIR).

(a)

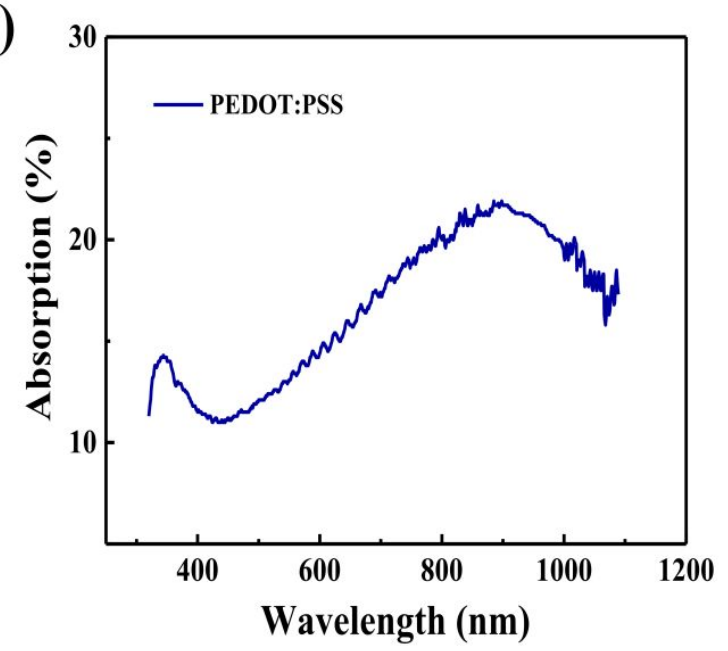

(b)

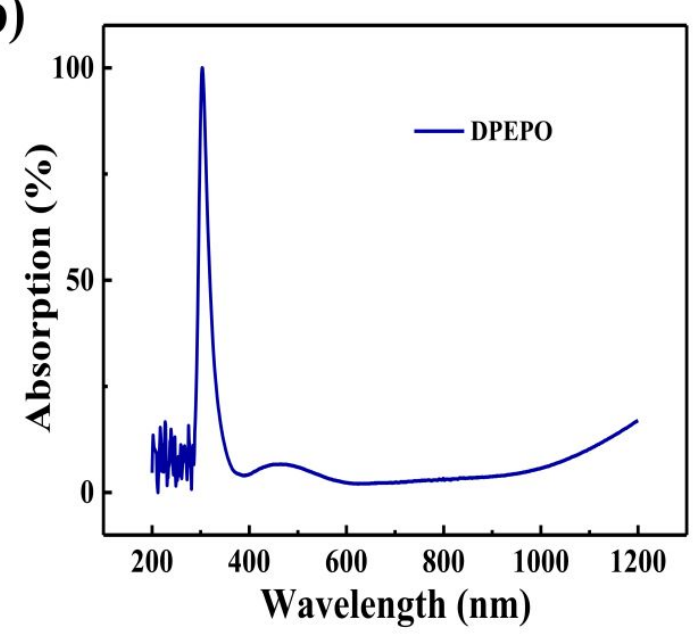

Figure S5. The absorption curves of organics. (a) PEDOT:PSS (b) DPEPO.

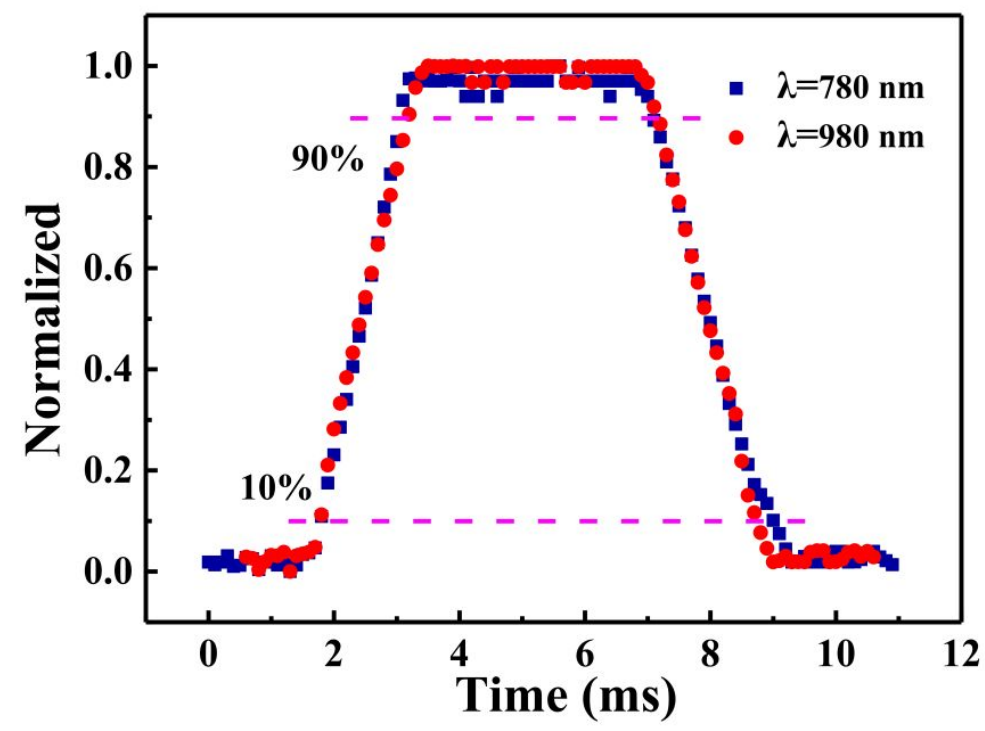

Figure S6. The response time of $\mathrm{Cd}_{3} \mathrm{As}_{2} / \mathrm{PEDOT}$ :PSS heterojunction thin film photodetector at the wavelength $780 \mathrm{~nm}$ and $980 \mathrm{~nm}$.

Diffusion time calculation method: The carrier mobility of $\mathrm{Cd}_{3} \mathrm{As}_{2} / \mathrm{DPEPO}$ and $\mathrm{Cd}_{3} \mathrm{As}_{2} / \mathrm{PEDOT}$ :PSS composite thin film was tested by hall effect test system (HMS2000). The carrier mobility is $3.23 \mathrm{~cm}^{2} \mathrm{v}^{-1} \mathrm{~s}^{-1}$ and $30.7 \mathrm{~cm}^{2} \mathrm{v}^{-1} \mathrm{~s}^{-1}$, respectively. Under the electric field, the average diffusion velocity $\left(v_{d}\right)$ of the carrier is proportional to the electric field intensity $(E)$. They satisfy the following relationship: $v_{d}=\mu E=\mu U / L$. 
Then the diffusion time $\left(\tau_{d}\right)$ and velocity $\left(v_{d}\right)$ satisfy the following relationship: $\tau_{d}=L / v_{d}=L^{2} / \mu U$. Where $L$ represents the channel length of the device, $U$ represents the voltage at both ends of the device when testing response time. In this experiment, the device is a planar heterojunction structure, where if the material thickness $(100 \mathrm{~nm})$ is ignored, $L$ can be approximately considered as the length of the channel ( $L=100 \mu \mathrm{m})$, and the bias voltage $(U)$ is $0.1 \mathrm{~V}$ in the test. According to the above formula, the $\tau_{d}$ of $\mathrm{Cd}_{3} \mathrm{As}_{2} / \mathrm{DPEPO}$ and $\mathrm{Cd}_{3} \mathrm{As}_{2} / \mathrm{PEDOT}$ :PSS material is calculated as $0.27 \mathrm{~ms}$ and 32.6 $\mu \mathrm{s}$, respectively.

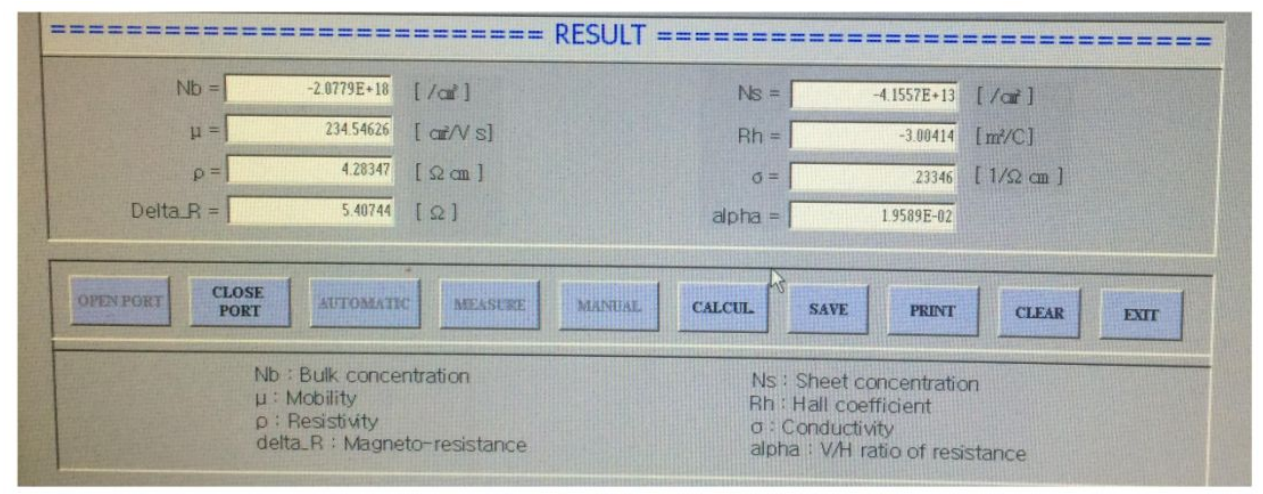

Figure S7. The hall (HDMS-2000) test results of prepared $\mathrm{Cd}_{3} \mathrm{As}_{2}$ thin film. The hall coefficient is negative, which proves that the prepared thin film is $\mathrm{N}$-type semiconductor material.

Table S1. The comparison of $\mathrm{Cd}_{3} \mathrm{As}_{2}$-based devices' performance in this work and similar devices previously reported.

\begin{tabular}{|c|c|c|c|c|c|}
\hline Active materials & $\begin{array}{c}\mathbf{R}_{\mathbf{i}} \\
(\mathbf{m A} / \mathbf{W})\end{array}$ & $\begin{array}{l}\text { Wavelength range } \\
\text { (nm) }\end{array}$ & $\begin{array}{c}\tau_{\text {on }} / \tau_{\text {off }} \\
(\mathbf{m s})\end{array}$ & $\begin{array}{l}\text { On-off } \\
\text { ratio }\end{array}$ & Ref \\
\hline $\begin{array}{l}\mathrm{Cd}_{3} \mathrm{As}_{2} \text { crystal } \\
\text { nanowire/plate }\end{array}$ & 5.9 & $532 \sim 10600$ & l & 130 & 1 \\
\hline $\begin{array}{l}\mathrm{Cd}_{3} \mathrm{As}_{2} \text { crystal } \\
\text { platelets }\end{array}$ & 0.27 & 1064 & / & 5 & 2 \\
\hline $\begin{array}{c}\text { Pure } \mathrm{Cd}_{3} \mathrm{As}_{2} \\
\text { thin film }\end{array}$ & 12.48 & $450 \sim 10600$ & $150 / 276$ & 12 & 3 \\
\hline $\begin{array}{c}\mathrm{Cd}_{3} \mathbf{A s}_{2} / \text { Pentacene } \\
\text { thin film }\end{array}$ & 36.15 & $450 \sim 10600$ & $30 / 60$ & 107 & 3 \\
\hline TaAs crystal & 0.7 & $438 \sim 10290$ & $200 / 300$ & 45 & 4 \\
\hline $\mathrm{MoTe}_{2}$ & 0.4 & $532 \sim 10600$ & / & I & 5 \\
\hline $\mathrm{MoTe}_{2} / \mathrm{MoS}_{2}$ & 0.6 & $332 \sim 800$ & $3.5 / 8.2$ & I & 6 \\
\hline $\mathrm{MoS}_{2}$ & 50.7 & $445-2717$ & / & I & 7 \\
\hline $\begin{array}{l}\mathrm{Cd}_{3} \mathrm{As}_{2} / \mathrm{DPEPO} \\
\text { thin film }\end{array}$ & 729 & $365 \sim 10600$ & $9.7 / 11.4$ & 6268 & $\begin{array}{l}\text { This } \\
\text { work }\end{array}$ \\
\hline $\begin{array}{c}\mathrm{Cd}_{3} \mathrm{As}_{2} / \text { PEDOT:PSS } \\
\text { thin film }\end{array}$ & 104 & $405 \sim 10600$ & $0.282 / 0.517$ & 1071 & $\begin{array}{l}\text { This } \\
\text { work }\end{array}$ \\
\hline
\end{tabular}




\section{References}

(1) Wang, Q.; Li, C. Z.; Ge, S.; Li, J. G.; Lu, W.; Lai, J.; Liu, X.; Ma, J.; Yu, D. P.; Liao, Z. M.; Sun, D., Ultrafast Broadband Photodetectors Based on Three-Dimensional Dirac Semimetal $\mathrm{Cd}_{3} \mathrm{As}_{2}$. Nano Lett. 2017, 17, 834-841.

(2) Yavarishad, N.; Hosseini, T.; Kheirandish, E.; Weber, C. P.; Kouklin, N. Room-Temperature Self-Powered Energy Photodetector Based on Optically Induced Seebeck Effect in $\mathrm{Cd}_{3} \mathrm{As}_{2}$. Appl. Phys. Express 2017, 10, 052201.

(3) Yang, M.; Wang, J.; Han, J.; Ling, J.; Ji, C.; Kong, X.; Liu, X.; Huang, Z.; Gou, J.; Liu, Z.; Xiu, F.; Jiang, Y., Enhanced Performance of Wideband Room Temperature Photodetector Based on $\mathrm{Cd}_{3} \mathrm{As}_{2}$ Thin Film/Pentacene Heterojunction. ACS Photonics 2018, 5, 3438-3445.

(4) Chi, S.; Li, Z.; Xie, Y.; Zhao, Y.; Wang, Z.; Li, L.; Yu, H.; Wang, G.; Weng, H.; Zhang, H.; Wang, A Wide-Range Photosensitive Weyl Semimetal Single Crystal-TaAs. Adv. Mater. 2018, 30, e1801372.

(5) Lai, J.; Liu, X.; Ma, J.; Wang, Q.; Zhang, K.; Ren, X.; Liu, Y.; Gu, Q.; Zhuo, X.; Lu, W.; Wu, Y.; Li, Y.; Feng, J.; Zhou, S.; Chen, J. H.; Sun, D., Anisotropic Broadband Photoresponse of Layered Type-II Weyl Semimetal MoTe 2 . Adv. Mater. 2018, 30, e1707152.

(6) Pezeshki, A.; Shokouh, S. H.; Nazari, T.; Oh, K.; Im, S., Electric and Photovoltaic Behavior of a Few-Layer Alpha-MoTe $2 \mathrm{MoS}_{2}$ Dichalcogenide Heterojunction. Adv. Mater. 2016, 28, 32163222 .

(7) Xie, Y.; Zhang, B.; Wang, S.; Wang, D.; Wang, A.; Wang, Z.; Yu, H.; Zhang, H.; Chen, Y.; Zhao, M.; Huang, B.; Mei, L.; Wang, J., Ultrabroadband $\mathrm{MoS}_{2}$ Photodetector with Spectral Response from 445 to $2717 \mathrm{~nm}$. Adv. Mater. 2017, 29, 1605972. 